\title{
ФЕНОМЕН ДЕТСКОГО АУТИЗМА \\ С ТОЧКИ ЗРЕНИЯ ОНТОГЕНЕТИЧЕСКИХ ЗАКОНОМЕРНОСТЕЙ РАЗВИТИЯ
}

\begin{abstract}
Аннотация. В статье рассматривается проблема детского аутизма с точки зрения предложенной автором периодизации онтогенеза, в которой каждый возрастной этап рассматривается как программа, ремающая определенную проблему развития. Согласно автору при детском аутизме нарушается процесс решения проблемы первого этапа онтогенеза - формирования субъекта видовой активности. Предполагается, ито основные симптомы детского аутизма являются результатом видового отчуждения.

Ключевые слова: психология, ранний детский аутизм, онтогенетическая проблема развития, перестройки самосознания, кризисы развития, субъект видовой активности, кризис трёх лет, видовое самосознание, Я-концепщия, видовая отчуждённость.
\end{abstract}

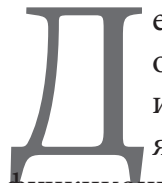

етский аутизм обычно определяется как «... общее расстройство развития - аномальное и/или нарушенное развитие, которое проявляется в возрасте до 3 лет аномальным функционированием во всех случаях социального взаимодействия, общения...» ${ }^{1}$. Однако остается неясным, какие именно закономерности онтогенеза нарушены при аутизме.

Считается, что при аутизме задерживается развитие когнитивных функций и речи ${ }^{2}$ или же эмоциональной сферы $^{3}$, что и приводит к расстройствам социальных взаимоотношений. Имеют место и противоположные мнения, согласно которым процесс психического развития ребенка искажается в результате отсутствия общения ${ }^{4}$. Как известно, при аутизме расстройство общения возникает уже в период новорожденности, когда когнитивные функции и эмоциональная сфера только начинают формироваться. Более того, можно говорить и о видовой отчужденности ребенка, что

\footnotetext{
1 Гиндикин В.Я. Лексикон малой психиатрии. М.: КронПресc, 1997. С. 495-496.

2 Rutter M. Cognitive deficits in the pathogenesis of autism // Journal of Child Psychology and Psychiatry. 1983. № 24.

3 Baron-Cohen S. Social and pragmatic deficits in autism: cognitive or affective? // Journal of Autism and Disorders. 1988. № 18.

4 Лебединская К.С. Нарушения эмоционального развития как клинико-дефектологическая проблема. М.: НИИ дефектологии РАО, 1992.
}

является причиной отсутствия мотивации общения с людьми у детей, страдающих аутизмом. При этом у них в основном не нарушены отношения с предметным миром: «...Джин любила только инструменты и механизмы, - пишет Э. Эриксон, - ...ляядя на них, она улыбалась, что-то им шептала и крепко обнимала. Само их присутствие приводило девочку в движение что-то вроде возбужденного танца и, тем не менее, она оставалась абсолютно равнодушной к людям.... ${ }^{5}$. С этой точки зрения можно предположить, что нарушения когнитивных функций, эмоциональной сферы и общения при раннем детском аутизме обусловлены более глубинными механизмами - дефектами программы развития первого цикла онтогенеза - формирования субъекта видовой активности.

Для пояснения сказанного, вкратце представим теоретические представления, лежащие в основе этой гипотезы. Согласно предложенной нами возрастной периодизации каждый этап онтогенеза рассматривается как процесс разрешения определенной «био-психосоциальной» проблемы (имеется в виду, что проблема развития актуализируется и решается на всех трех уровнях).

Под понятием «проблема развития», мы понимаем генетически заданную, отраженную на психологическом и социальном уровне, данную в определенных условиях развития «цель», конечный результат, на достижение

5 Эриксон Э. Детство и общество. СПб: Ленато, 1996. С. 281. 


\section{Клиническая психология}

которой направлен процесс онтогенеза на конкретном возрастном этапе. При этом проблемы развития мы не рассматриваем как субъективные феномены, в основе которых лежат сознательные цели. Они существуют объективно и отражают естественные «цели» развития, сформированные в процессе эволюции. Именно эти естественные «цели» отражают смысл и основное направление процесса развития, определяют особенности новообразований на каждом возрастном этапе. При этом биологические, психические и социальные возрастные новообразования каждого этапа развития не являются случайными и независимыми друг от друга, каждый из них является шагом в системном процессе достижения некоторой конечной «цели». Анализ этих новообразований дает возможность выявить проблему развития каждого возрастного этапа и программу, направленную на решение этой проблемы.

На основе анализа системы новообразований основных циклов развития человека (детство, отрочество, зрелость, старость) нами были выделены четыре проблемы развития и, соответственно, четыре возрастных этапа, направленных на их решение. На первом цикле формируется субъект видовой активности (от зачатия до 7-8 лет), на втором - субъект половой активности (8, 9-18, 22 лет), третий цикл направлен на формирование субъекта социальной (семейной и трудовой) активности $(20,22-$ 45 лет), а на четвертом цикле происходит самореализация и самоисчерпание личности (от 35, 45 лет до конца жизни). На каждом цикле происходит перестройка самосознания, в результате которой человек осознает себя субъектом определенной активности (видовой, половой, социальной, а на последнем этапе личность осознает себя смертным). Более подробно об этой периодизации и перестройках самосознания можно прочитать в нашей статье представленной в интернете $^{6}$, здесь же мы проанализируем онтогенетические закономерности первого цикла развития, которые, на наш взгляд, могут пролить свет на некоторые аспекты раннего детского аутизма.

В этом цикле развития можно выделить три этапа. На первом этапе (от зачатия до рождения) проблема решается в основном на биологическом уровне, формируются органические видовые свойства. При этом «...эмбрион в своем развитии вначале отражает черты, свойственные типу в целом, затем черты класса, отряда и т.д., из более общего образуется менее общее и т.д., пока, наконец, не образуется самое специальное,

6 Худоян С.С. К проблеме построения объясняющей возрастной периодизации // Ярославский Педагогический Вестник, 2007. № 1. (http://www.yspu.yar.ru/vestnik/pedagoka_i_ psichologiy/34_7/). присущее представителям соответствующего вида» ${ }^{7}$. На втором этапе этого цикла (от рождения до трех лет) формируются психические видовые свойства. Уже в период новорожденности ребенок проявляет особую чувствительность к человеческим лицам и голосам, а в конце этого периода появляется комплекс оживления. Наиболее логичное объяснение этих феноменов, на наш взгляд, является то, что ребенок, благодаря определенным генетическим механизмам, начинает узнавать, а потом и принимать свой вид. Это своеобразный период импринтинга, которое играет важную роль в формировании видовой идентичности. По этому поводу М. Трунов и Л. Китаев пишут: «Благодаря явлению импринтинга, например, во время первичного контакта матери и ребенка сразу после рождения между ними образуется сильная психоэмоциональная связь, основа их будущих взаимоотношений, «включается» способность матери непосредственно ощущать потребности младенца и чувствовать его состояние. Ребенок запечатлевает принявший его мир в форме первичных внеутробных ощущений, и эти ощущения - основа его взаимоотношений с этим миром, фон, на котором будет строиться его сознательное отношение к миру» ${ }^{8}$. Как известно, в период новорожденности аутичные дети проявляют безразличие как к человеческим лицам, так и к голосам, (предпочитают не речевые звуки ${ }^{9}$ ), что, на наш взгляд, нарушает процесс импринтинга, в результате чего к концу второго месяца не появляется комплекс оживления, т.е. не происходит принятие своего вида и отнесение себя к этому виду. Эти нарушения затрудняют процесс формирования социально-психологических новообразований, направленных на становление субъекта видовой активности. Так, нарушается нормальное развитие привязанности (attachment) ${ }^{10}$, например, дети с аутизмом не тянутся на руки, не обнимают мать, избегают телесного контакта. Нарушается также развитие совместной деятельности, понимание людей (их эмоций, намерений), способность к эмпатии, различения своих и чужих т.п. К концу первого года у ребенка начинает формироваться важнейшее видовое свойство - речь,

\footnotetext{
Аршавский И.А. Физиологические механизмы и закономерности индивидуального развития. М.: Наука, 1982. С. 45.

8 Трунов М., Китаев Л. Экология младенчества. Первый год. М.: Ирис-Пресс, 1993. С. 36.

9 Мэш Э., Вольф Д. Детская патопсихология. Нарушения психики ребенка М.; СПб.: Прайм еврознак, 2003.

10 Zaslow R., Menta M. The psychology of the Z-process: Attachment and activity, San Jose, CA: San Jose University Press, 1975.
} 


\section{Психология и психотехника 5(56) • 2013}

благодаря которой формируются другие, не менее важные свойства - сознание, мышление, ребенок начинает усваивать общественно-исторический опыт человечества. При аутизме имеют место нарушения речи, однако не происходят серьезные расстройства мышления. По всей вероятности, это связано с тем, что при аутизме нарушается развитие коммуникативного аспекта речи, а внутренняя речь, на которой основывается мышление, остается сохранным и даже интенсивно развивается.

Специфической особенностью онтогенеза человека является то, что процесс развития происходит в двух принципиально разных формах - спонтанно и сознательно. Спонтанное развитие происходит, в основном, по биологическим и социальным программам. На этом уровне проблема, на разрешение которой направлен процесс развития, не актуальна для субъекта, он не воспринимает себя ее носителем и не осуществляет целенаправленную деятельность для ее разрешения. Однако в определенный период каждого возрастного цикла человек начинает ясно осознавать направление собственного развития, себя как субъекта этого процесса, а решение проблемы развития осуществляется, в основном, на сознательном уровне.

В первом цикле онтогенеза этот период начинается в начале третьего этапа, приблизительно с трех лет. У ребенка появляется важнейшее видовое свойство самосознание, благодаря которому решение проблемы развития получает сознательный характер - ребенок целенаправленно усваивает формы человеческого поведения и систему взаимоотношений в обществе, функционирует как полноценное человеческое существо. В лексиконе ребенка появляются личные местоимения, что свидетельствует не только о применении новых языковых средств, но также и о формировании важного обобщения и дифференциации, относительно собственного «Я». Ребенок дифференцирует свое «Я» от «не-Я» и начинает осознавать и идентифицировать со своим «Я» все, что принадлежит ему - желания, действия, предметы (он уже не говорит «Максим ест», а «Я ем», «Я хочу», «Я делаю»). На этой основе начинают проявляться его собственнические стремления («Это мое», «Моя игрушка»). С этой точки зрения, этот период развития можно считать критическим не только в связи с пробуждением самосознания, но еще и воли. Впервые ребенок противопоставляет свою волю воле других и своим желаниям («Я хочу, но нельзя»).

Важной особенностью самосознания детей дошкольного возраста является то, что оно носит видовой характер, т.е. ребенок осознает себя, как человеческое существо. Видовое самосознание является диффузным, не имеет четких дифференциа- ций, например, половой сферы, социальных ролей. Н.И. Непомнящая характеризует самосознание детей этого возраста следующим образом: «...Эта первоначально диффузная выделенность себя, своего «Я» (в отличие от не-Я) начинает связываться с теми или иными областями деятельности и отношений, которые объективно выделяются для ребенка...» ${ }^{11}$. Подобное самосознание дает ребенку возможность брать на себя любую социальную роль, идентифицировать себя с другими людьми, животными и даже неодушевленными предметами (как во время игр, так и вне игровой ситуации). Причем, в результате отсутствия четкой половой дифференциации, ребенок может свободно имитировать поведенческие формы, социальные роли противоположного пола, например, маленький мальчик может верить, что он беременный ${ }^{12}$.

После пробуждения самосознания, ребенок с одной стороны начинает изучать, что собой представляет человек (это проявляется, например, в рисунках детей этого возраста), с другой - «экспериментировать» собой и самоутверждаться в качестве полноценного человека (например, в ролевых играх). «...До трех лет, пишет С.А. Болдырева, - ребенок вообще едва понимает какой след оставляет на листе бумаги карандаш. Но как только появляется это удовольствие, в 99 из 100 случаев ребенок изображает человека в виде четырехугольника или кружочка с отходящими от них двумя перпендикулярными линиями» ${ }^{13}$.

Дети этого возраста тщательно изучают взрослых, идентифицируются с ними, имитируют их манеры, поведение, в ролевых играх воспроизводят разные стороны жизни взрослых. Как отмечает Д.Б. Эльконин: «Результаты данных исследований показывают, что ролевая игра особенно чувствительна к сфере человеческой деятельности, труда и отношений между людьми и, следовательно, основным содержанием роли, которую берет на себя ребенок, становится воспроизведение именно этой стороны действительности» ${ }^{14}$. Фактически, играя роли взрослых, ребенок отождествляется с ними, тем самым принимает и заставляет других принять себя полноценным человеком. То же самое происходит и вне игровой ситуации. Ребенок, имитируя поведение взрослых или

11 Непомнящая Н. И. Основные компоненты психологической структуры личности // Опыт системного исследования психики ребенка / под ред. Н.И. Непомнящей. М.: Педагогика, 1975. С. 34.

12 Эриксон Э. Детство и общество. СПб.: Ленато, 1996.

13 Болдырева С.А. Рисунки детей дошкольного возраста больных шизофренией. М.: Медицина, 1974. С. 18.

14 Эльконин Д.Б. Избранные психологические труды. М.: Просвещение, 1989. С. 322. 
проявляя своеволие, самостоятельность («Я сам») и т.п., фактически осуществляет сознательную деятельность, направленную, с одной стороны, на усвоение форм человеческого поведения, а с другой - на самоутверждение в качестве полноценного человека. Ребенок пытается также на словах убедить взрослых, пожалуй, и самого себя, что он полноценный человек, например, заявляет, что он взрослый, придумывает истории о своей взрослой жизни (которые часто напоминают бред). Так, маленький мальчик может заявить, что он женат, имеет детей, что у него машина, работает водителем и т.д.

Наши исследования показали, что для ребенка понятия «взрослый» и «полноценный человек» синонимичны, он не воспринимает себя взрослым по возрасту или по физическим характеристикам, а просто настаивает на своей полноценности ${ }^{15}$. Как замечает В.С. Мухина, дети дошкольного возраста приписывают себе многочисленные положительные качества - силу, храбрость, ум, хвастаются по любому поводу, совершенно не думая, насколько сказанное соответствует действительности ${ }^{16}$. Ребенок может бороться даже за полноценность своего имени. «Все, что имеет отношение к имени ребенка, приобретает для него особый, личностный смысл» ${ }^{17}$. Столь сильное стремление к самоутверждению свидетельствует о наличии у ребенка (по всей вероятности на уровне подсознания) сомнений по поводу собственной полноценности или даже чувства неполноценности (адлеровский комплекс неполноценности). Ребенок, сравнивая себя с взрослыми, начинает сомневаться, что он является таким же полноценным человеком, как и они. Как показали наши исследования, симптомы кризиса трех лет направлены на преодоление этой неполноценности и формирование положительной самооценки. К концу кризиса формируется концепция собственного «Я» как человеческого существа. Эта концепция основываться на положительной, отрицательной или же самоотвергающей самооценке. В последнем случае ребенок может отчуждаться от самого себя и даже войти в образ не-Я18.

В кризисном периоде начинают формироваться и другие аспекты Я-концепции. «В возрасте от трех с половиной до четырех лет, - пишет Р. Бернс, - дети начинают различать свое внешнее, или физическое «Я», то есть тело, которое видят другие люди, и внутреннюю

15 Худоян С.С. Онтогенетические перестройки самосознания и кризисы развития личности. Ереван: Зангак-97, 2010.

16 Мухина В.С. Детская психология. М.: Просвещение, 1985. C. 173.

17 Там же. С. 111.

18 Салливан Г.С. Интерперсональная теория психиатрии. М.: СПб, 1999.
Я-концепцию, скрытую от окружающих» ${ }^{19}$. Одним из важных подструктур системы «Я» является идеальное «Я», которое, по всей вероятности, тоже начинает формироваться приблизительно в период от 3 до 5 лет (в этом возрасте, идеальное «Я» часто базируется на родительском образе - «Вырасту, стану как папа») ${ }^{20}$. Формирование морали в 4-5 лет ${ }^{21}$ также свидетельствует о том, что идеальное «Я» дифференцируется именно в этом возрасте. Таким образом, на третьем этапе первого цикла онтогенеза формируются важнейшие видовые характеристики ребенка - самосознание, система Я, Я-концепция, воля, основные черты личности (3. Фрейд), ребенок в социальном плане становится субъектом видовой активности, усваивает социальные роли, видовые поведенческие навыки (как одеваться, кушать, вести себя в обществе и др.), вступает в систему социальных взаимоотношений. Именно в результате этих крупных изменений этот этап развития является переломным не только в формировании личности как субъекта видовой активности, но и различных психических заболеваний. В основном с этого возраста начинают появляться различные невротические расстройства, детская шизофрения, а аутизм проявляет себя в полной мере. Именно с этого возраста обычно ставят диагноз раннего детского аутизма ${ }^{22}$. В первую очередь проблемы возникают в процессе формирования самосознания. Адекватное применения личных местоимений, в частности местоимения «Я» значительно задерживается. Если в норме уже в 2-2,5 года дети употребляют личные местоимения, то дети с аутизмом даже в 5 лет не различают местоимения, не реагируют и не называют свое имя, не узнают себя и других людей на фотографии, в зеркале, не дифференцируют части тела, не осознают свой возраст, у них не сформирована самооценка ${ }^{23}$.

Отметим, что это избирательное недоразвитие, эти дети отлично ориентируются в мире предметов, классифицируют объекты, хорошо общаются с животными ${ }^{24}$.

19 Бернс Р. Развитие Я концепции и воспитание. М.: Прогресс, 1986. С. 106.

20 Тайсон Ф., Тайсон Р. Психоаналитические теории развития. Екатеринбург: Деловая книга, 1998.

21 Массен П., Конджер Дж., Каган Дж., Хьюстон А. Развитие личности ребенка М.: Прогресс, 1987. С. 164.

22 Аппе Ф. Введение в психологическую теорию аутизма М.: Теревинф, 2006.

23 Пробылова В.С. Особенности самосознания пятилетних детей с ранним детским аутизмом: автореф. дисс. ... канд. псх. н. Н. Новгород, 2008. 26 с.

24 Hobson, R.P. Beyond cognition: a theory of autism. In Autism: nature, diagnosis and treatment, G. Dawson (ed.). New York: Guildford Press, 1989. 


\section{Психология и психотехника 5(56) • 2013}

Если при детской шизофрении в период формирования самосознания происходят бредовые метаморфозы «Я» (бред метаморфозы), ребенок считает себя животным, неодушевленным предметом, то дети с аутизмом просто фантазируют об этом (по всей вероятности из за отсутствия психотических защитных механизмов), требуя от окружающих, считать их животным, не называть их по имени, кормить как животных ${ }^{25}$ и т.п.

Важную информацию о процессе формирования самосознания дают детские рисунки. На их основе можно судить об особенностях восприятия и принятия своего «Я», о самооценке и т.п. В рисунках детей дошкольного возраста страдающих аутизмом, также как и шизофренией проявляется явная видовая отчужденность. И те и другие любят рисовать и очень хорошо рисуют, но не любят и даже отказываются рисовать людей ${ }^{26}$. Эти дети обычно рисуют дома, машины, животных, абстрактные фигуры. Несколько отклоняясь, хотим представить очень интересный факт, связанный с рисунками детей страдающих шизофренией. Они часто рисуют получеловека - полуживотного 27 . Подобные рисунки, по всей вероятности, свидетельствуют о видовой неопределенности и смешении в самосознании ребенка. Интересно, что в фольклоре и изобразительном искусстве раннего периода истории многих народов присутствует образ человека - животного, что дает основание предположить, что исторически, первичное самосознание человека также носило видовой характер, которому предшествовал период видовой неопределенности. Например, легенда о сфинксе, пожалуй, и есть отголосок периода видовой неопределенности в самосознании человека.

Представленные выше факты свидетельствуют, что видовая отчужденность при аутизме проявляется также в процессе формирования самосознания, задерживая или отклоняя нормальное развитие. Это, в свою очередь, отражается на игровой деятельности, которая является важнейшим средством видовой социализации ребенка. Об игре аутичных детей В.П. Критская с соавторами пишут: «Общей чертой исследованных нами детей, характеризующихся в первую очередь чертами аутизма и диссоциации психического развития, было то, что ни на одном возрастном этапе они не играли со сверстниками в сюжетные игры, не принимали социальных ролей, не воспроизводили в играх ситуаций, отражающих реальные жизненные

25 Сухарева Г.Е. Лекции по психиатрии детского возраста. М.: Медицина, 1974.

26 Болдырева С.А. Рисунки детей дошкольного возраста больных шизофренией. М.: Медицина, 1974.

27 Там же. С. 39. межлюдские отношения: профессиональные, семейные и т.д. Интерес и склонность к воспроизведению такого рода взаимоотношений у них отсутствовали» ${ }^{28}$. Согласно данным Т.Л. Шишовой, аутичные дети не играют с куклами и даже боятся их, в то время, как плюшевые игрушки животных у них не вызывают страха $^{29}$.

Завершая эту статью, попробуем представить те выводы, к которым мы пришли в результате этого исследования. Недоразвитие или аномальное развитие при аутизме является избирательным, относится к процессу формирования субъекта видовой активности. Когнитивные и эмоциональные расстройства в основном относятся к сфере общения со своим видом (людьми), но не с предметным миром или с животными. Основной характеристикой этого расстройства является видовая отчужденность, а аутизм формируется в результате этого отчуждения (с этой точки зрения данное расстройство можно обозначить как синдром видового отчуждения). По всей вероятности, при некоторых видах детской шизофрении также имеет место видовая отчужденность (об этом свидетельствуют такие симптомы как аутизм, отказ от видовых свойств речи, прямохождения, перевоплощение в животных и др.), которая, однако, проявляется после 2,5-3 лет, т.е. после формирования самосознания и может являться результатом отрицательного развития кризиса трех лет, отвергания своего видового «Я».

Основные симптомы аутизма связаны с нарушением формирования видовых новообразований (узнавание и принятие своего вида, потребность в общении со своим видом, речь, символическая функция, формирование видовых форм поведения и др.). При этом симптомы аутизма можно рассматривать в причинно-следственной иерархии (не в одном ряду), где одни нарушения определяют появление других (например, непринятие своего вида приводит к затруднению общения, а это затрудняет процесс усвоения речи, что в свою очередь обуславливает особенности мышления и восприятия мира и т.п.). В основе этой иерархии, на наш взгляд, лежат нарушения инстинктивных механизмов узнавания своего вида (проявляется в чувствительности новорожденного к человеческим лицам и голосам), его принятия и видовой самоидентификации (проявляются в комплексе оживления). Трудно сказать, какую роль играют в этом врожденном дефекте биологические

28 Критская В.П., Мелешко Т.К., Поляков Ю.Ф. Патология психической деятельности при шизофрении: мотивация, общение, познание. М.: Изд-во МГУ, 1991.

29 Шишова Т.Л. О чем свидетельствуют детские рисунки (http://www.portal-slovo.ru/pedagogy/38106.php?ELEMENT_ $\mathrm{ID}=38106$ ) 


\section{Клиническая психология}

(дефекты генов, функционирования мозга) и психологические факторы (отрицательные психологические воздействия в эмбриональном периоде, отсутствие ключевых сигналов, стимулирующих импринтинг, узнавание вида), но можно утверждать, что и те, и другие имеют место в формировании аутизма.

\section{Список литературь:}

1. Аппе Ф. Введение в психологическую теорию аутизма М.: Теревинф, 2006. 216 с.

2. Аршавский И.А. Физиологические механизмы и закономерности индивидуального развития. М.: Наука, 1982. $270 \mathrm{c}$.

3. Бернс Р. Развитие Я концепции и воспитание. М.: Прогресс, 1986. 421 с.

4. Болдырева С.А. Рисунки детей дошкольного возраста больных шизофренией. М.: Медицина, 1974.160 с.

5. Гиндикин В.Я. Лексикон малой психиатрии. М.: Крон-Пресс, 1997. 576 с.

6. Критская В.П., Мелешко Т.К., Поляков Ю.Ф. Патология психической деятельности при шизофрении: мотивация, общение, познание. М.: Изд-во МГУ, 1991. 256 с.

7. Лебединский В.В. Нарушения психического развития у детей: учебное пособие. М.: Изд-во Московского университета, 1985. 167 с.

8. Массен П., Конджер Дж., Каган Дж., Хьюстон А. Развитие личности ребенка М.: Прогресс, 1987. 272 с.

9. Мухина В.С. Детская психология, М.: Просвещение, 1985. 272 с.

10. Непомнящая Н.И. Основные компоненты психологической структуры личности // Опыт системного исследования психики ребенка / под ред. Н.И. Непомнящей. М.: Педагогика, 1975. 66 с.

11. Пробылова В.С. Особенности самосознания пятилетних детей с ранним детским аутизмом: автореф. дисс. ... канд. псх. н. Н. Новгород, 2008. 26 с.

12. Худоян С.С. Онтогенетические перестройки самосознания и кризисы развития личности. Ереван: Зангак-97, 2010. 232 c.

13. Эриксон Э. Детство и общество. СПб.: Ленато, 1996. 592 с.

14. Baron-Cohen S. Social and pragmatic deficits in autism: cognitive or affective? // Journal of Autism and Developmental Disorders. 1988. № 18. P. 379-402.

\section{References (transliteration):}

1. Appe F. Vvedenie v psikhologicheskuyu teoriyu autizma M.: Terevinf, 2006. $216 \mathrm{s.}$

2. Arshavskiy I.A. Fiziologicheskie mekhanizmy i zakonomernosti individual'nogo razvitiya. M.: Nauka, 1982.270 s.

3. Berns R. Razvitie Ya kontseptsii i vospitanie. M.: Progress, 1986. $421 \mathrm{s.}$

4. Boldyreva S.A. Risunki detey doshkol'nogo vozrasta bol'nykh shizofreniey. M.: Meditsina, 1974. 160 c.

5. Gindikin V.Ya. Leksikon maloy psikhiatrii. M.: Kron-Press, 1997. 576 s.

6. Kritskaya V.P., Meleshko T.K., Polyakov Yu.F. Patologiya psikhicheskoy deyatel'nosti pri shizofrenii: motivatsiya, obshchenie, poznanie. M.: Izd-vo MGU, 1991. 256 s.

7. Lebedinskiy V.V. Narusheniya psikhicheskogo razvitiya u detey: uchebnoe posobie. M.: Izd-vo Moskovskogo universiteta, 1985. $167 \mathrm{~s}$.

8. Massen P., Kondzher Dzh., Kagan Dzh., Khyuston A. Razvitie lichnosti rebenka M.: Progress, 1987.272 s.

9. Mukhina V.S. Detskaya psikhologiya, M.: Prosveshchenie, 1985. 272 s.

10. Nepomnyashchaya N.I. Osnovnye komponenty psikhologicheskoy struktury lichnosti // Opyt sistemnogo issledovaniya psikhiki rebenka / pod red. N.I. Nepomnyashchey. M.: Pedagogika, 1975. 66 s.

11. Probylova V.S. Osobennosti samosoznaniya pyatiletnikh detey s rannim detskim autizmom: avtoref. diss. ... kand. pskh. n. N. Novgorod, 2008. 26 s.

12. Khudoyan S.S. Ontogeneticheskie perestroyki samosoznaniya i krizisy razvitiya lichnosti. Erevan: Zangak-97, 2010. 232 s.

13. Erikson E. Detstvo i obshchestvo. SPb.: Lenato, 1996. $592 \mathrm{s.}$

14. Baron-Cohen S. Social and pragmatic deficits in autism: cognitive or affective? // Journal of Autism and Developmental Disorders. 1988. № 18. P. 379-402. 